\title{
ZNAČAJ KULTURNE KOMPETENTNOSTI ZA SOCIJALNI RAD
}

Apstrakt: U radu su date problematizacija i analiza značaja kulturne kompetentnosti za socijalni rad, odnosno za praksu socijalnih radnika. Predstavljeni su koncepti i programi multikulturalizma i interkulturalizma kao šireg društvenog konteksta, a posebna pažnja posvećena je konceptu duboke kulture, kao i fenomenu interkulturnog učenja kao preduslovu za kulturno kompetentne prakse. Zatim se razmatraju sami fenomeni kulturne kompetentnosti i kulturno kompetentnih praksi, uz detaljno bavljenje potrebom za obrazovanjem (i postojanjem) kulturno kompetentnog socijalnog radnika.

Ključne reči: socijalni rad, multikulturno/interkulturno okruženje, duboka kultura, interkulturno učenje, kulturna kompetentnost.

Kao akademska disciplina i profesija socijalni rad izučava one društvene interakcije među ljudima koje utiču na njihove sposobnosti da ostvare svoje aspiracije i vrednosti. U tom smislu, može se govoriti o njegova četiri glavna cilja. Prvi je uvećanje kapaciteta ljudi za rešavanje problema i izlaženje na kraj sa životnim teškoćama i problemima, drugi je povezivanje ljudi sa sistemima koji im nude resurse, usluge i mogućnosti, treći je promovisanje efikasnog i humanog funkcionisanja tih sistema, a četvrti je doprinos razvoju i poboljšanju socijalne politike (Kirk \& Reid, 2002). U kontekstu ovog rada prvenstveno nas zanima problem kulturne kompetentnosti, naročito kada se radi o socijalnom radu u multikulturnom okruženju. Pošto se sistematsko znanje u socijalnom radu razvija od samih početaka profesije, iskristalisala su se dva glavna smera kojima su se akumulirali znanje i teorija. Jedan je empirijski zasnovana praksa, a drugi je primena teorija iz raznih društvenih nauka (prvenstveno psihologije i sociologije) na objašnjenje društvenih problema i razvoja intervencija pomoću kojih se ovi problemi mogu popraviti ili rešiti (Sheldon \& Macdonald, 2009). U konktestu kulturne kompetentnosti vrlo su važna (i) znanja iz antropologije.

Dakle, uprkos određenim preklapanjima između socijalnog rada, sociologije i psihologije, među njima postoje i izvesne jasne razlike. Uopšteno rečeno, sociologija izučava društvene grupe, organizacije, institucije i društva, psihologija 
individualno ponašanje i mentalne procese, a socijalni rad teži da interveniše između ljudi i njihovog društvenog okruženja i bavi se društvenim i ekonomskim uslovima koji utiču na individue, porodice, grupe, organizacije i zajednice i naglašava značaj multikulturnog razumevanja ljudi i zajednica. Takođe, unutar profesije socijalnog rada postoje izvesne tenzije koje su pre karakteristične za sociologiju nego za psihologiju, a prvenstveno se tiču relevantnosti i efikasnosti mikro i makro prakse. Uprkos tome, većina socijalnih radnika shvatila je da ono što socijalni rad čini jedinstvenim jeste sposobnost da se društveni problemi lociraju unutar kompleksne međupovezanosti individua, porodica, zajednica $i$ društava (van Wormer, 2007; Kirst-Ashman, 2008).

Bavljenje socijalnim radom zahteva i suprotstavljanje diskriminaciji i represiji koje neretko trpe korisnici usluga socijalne zaštite, odnosno koje perpetuiraju različiti pojedinci, grupe, zajednice i društvo u celini. Da bi to bilo moguće, važno je prepoznati manjinske, diskriminisane i marginalizovane grupe u nekom društvu ili kulturi. Različiti termini, poput multikulturalizma, interkulturalizma, diverziteta, kulturnog diverziteta, kroskulturne prakse itd. upotrebljavaju se za opis obrazaca interakcije u socijalnom radu sa različitim "posebnim populacijama" - tj. sa manjinskim, diskriminisanim i marginalizovanim individuama i grupama. Posebnu ulogu u tome ima koncept kulturne kompetentnosti, kao praksa koja počiva na multikulturalizmu, odnosno interkulturalizmu.

\section{MULTIKULTURALIZAM I INTERKULTURALIZAM: KONTEKST KULTURNO KOMPETENTNOG SOCIJALNOG RADA}

Multikulturalizam se neretko definiše kao politički pokret, ideologija i/ili kao socijalno-politička praksa koja sugeriše i prepoznaje da se društvo sastoji od različitih kulturnih grupa koje (treba da) imaju jednaki društveni status. U tom smislu on se suprotstavlja monokulturalizmu, koji implicira normativno kulturno jedinstvo i kulturnu homogenost. Pošto monokulturalizam pretpostavlja odbacivanje razlika i verovanje u superiornost dominantne kulture u nekom društvu, multikulturalizam samim tim označava prihvatanje, poštovanje i svojevrsno "slavljenje" i kulturnih sličnosti i kulturnih razlika među ljudima (vidi npr. Laden \& Owen, 2007). Kao koncept, multikulturalizam je istovremeno i izazovan i provokativan, a reakcije na njega su raznovrsne. One zavise i od socioekonomskih faktora, političkog okruženja, te od individualne ili lične orijentacije prema kulturnom pluralizmu. Među tim reakcijama mogu se naći i zagovaranje multikulturalizma, njegovo prihvatanje kao de facto stanja, sumnjičavost u pogledu njegovih korena i namera, sve do otvorenog odbacivanja od strane onih koji ga smatraju za pretnju.

U smislu ideala, multikulturalizam se posmatra i kao građansko i ljudsko pravo kulturnih grupa koje je ukorenjeno u ljudskom dostojanstvu i u fundamentalnoj jednakosti različitih kultura. Takođe, ključna komponenta multikulturalizma jeste kulturni diverzitet, u smislu da multikulturalizam počiva (i) na pluralnosti jezika, 
običaja, tradicija, normi, veština, perspektiva, životnih stilova i pogleda na svet. (Pre)poznavanje ovih razlika sugeriše da subordinirane društvene grupe i zajednice ne moraju da odustanu od svog identiteta ili da se asimiluju u skladu sa dominantnim normama ili obrascima ponašanja (Reitz, Breton, Dion, \& Dion, 2009). U skladu sa tim, prema multikulturalizmu, dominantne grupe su te koje moraju da steknu i razviju nove načine za razumevanje drugih i drugačijih kultura od sopstvene.

Multikulturno društvo između ostalog uključuje i kulturne razlike koje se tiču rase, etniciteta, verske pripadnosti, veština i sposobnosti, roda, seksualnosti, ekonomskog i društvenog položaja itd. Iz navedenih razloga, multikulturalizam se odnosi i na razlike unutar društva koje su istorijski i društveno konstruisane. Dominantne grupe u društvu neretko su definisane onim tradicijama koje podržavaju superiornost jednih grupa i kultura nad drugim grupama i kulturama (poput belaca, muškaraca itd.). Izazovi za razumevanje i prihvatanje kulturnih razlika obično se tiču etnocentrizma i ksenofobije, kao i predrasuda i zabluda koje postoje o drugim kulturama.

U užem smislu, multikulturalizam se opisuje kao sociopolitički pokret čiji cilj jeste da prepozna i afirmiše različita etnička porekla pripadnika određenog društva. Naime, etnički i kulturni diverzitet odlikuje većinu država sveta, a nakon završetka Hladnog rata dolazi do uvećanog značaja dimenzija etniciteta, religije i uopšte kulturnog porekla. S tim u vezi, tragedije poput genocida u Bosni i Hercegovini ili Ruandi uvećale su i pažnju koju pojedinačne države pridaju odnosima moći među različitim etničkim i verskim (pod)grupama u sopstvenim društvima. Nekoliko zemalja, poput Australije, Kanade i Švedske, otvoreno su i usvojile politike multikulturalizma kao odgovor na kulturni i etnički diverzitet koji odlikuje njihovo stanovništvo (NMAC, 1999; Kastoryano, 2009). U pitanju su politike koje prepoznaju postojanje etničkog diverziteta i koje su posvećene pravima individua da zadrže svoju kulturu paralelno sa ravnopravnim učešćem u društvenom i političkom životu svojih država. Zagovornici multikulturalizma insistiraju na tome da ove politike na pozitivan način doprinose i individuama $i$ društvu u celini time što redukuju pritiske i društvene sukobe zasnovane na diskriminaciji i nejednakosti.

Pokret multikulturalizma, koji se pojavljuje 1980-ih godina, prvobitno je predstavljao reakciju na evropocentrične pristrasnosti i predrasude, kao npr. u javnom diskursu, u školskim kurikulumima itd. (vidi npr. Race, 2011). Ova reakcija se reflektovala $u$ gradualnom uvođenju upotrebe mnogih jezika u zvaničnim dokumentima, u inkorporiranju figura različitog etničkog porekla u školske udžbenike i tome slično. Snažni zagovornici multikulturalizma i multikulturnih praksi tvrdili su da je na ovaj način moguće pronaći rešenje za dugu istoriju etničkih i rasnih konflikata. Sve češći zahtevi manjinskih grupa za priznanjem i jednakošću doveli su do širenja koncepta kulturnog diverziteta od tradicionalnih rasnih i etničkih podela do inkorporiranja i dimenzija roda, klase, religije, seksualne orijentacije, starosti, te fizičkih i mentalnih sposobnosti. 
S druge strane, konzervativno orijentisani političari su kritikovali pokret multikulturalizma kao devalvaciju onoga što su smatrali esencijalnim jezgrom sopstvene (zapadne, bele, muške, hrišćanske, heteroseksualne) kulture. Kritika ili skepsa u vezi sa multikulturalizmom obično se izražava u stavovima da on može da dovede do društvenog haosa i gubitka kontrole, da umanji osećaj patriotizma, iskvari nacionalni jezik, dovede u pitanje nacionalni identitet, stvori više mogućnosti za nekonformističko ponašanje, te razori moralne standarde koji regulišu ponašanje. Ipak, društvena teorija, istraživačka praksa, kao i višedecenijsko iskustvo nakon uvođenja različitih programa koji počivaju na ideji multikulturalizma jasno ukazuju na to da su ovakve kritike ili strahovi sasvim neopravdani, te ideološki konzervativni koliko i politički hazardni (Willett, 1998).

Kada je reč o interkulturalizmu, pod ovim pojmom se podrazumeva korisna društvena razmena u kojoj kulture prvenstveno uče jedne o drugima i na ovaj način multikulturalizam se posmatra samo kao (prvi) korak ka interkulturalizmu. Dakle, on podrazumeva i kroskulturni dijalog i aktivno učenje, umesto pasivnog prihvatanja multikulturalizma, tj. proste pluralnosti međusobno segregiranih $\mathrm{i} / \mathrm{ili}$ izolovanih kultura. Do ideje o interkulturalizmu dolazi nakon percepcije o ograničenom uspehu praksi multikulturalizma, odnosno o svojevrsnoj legitimizaciji (auto)segregacije i naglašavanja kulturnih razlika, umesto sličnosti i međusobnog preplitanja (Meer \& Modood, 2012).

Iz tih razloga, moguće je tvrditi da interkulturalizam nudi mnogo plodniji pristup od konvencionalnog multikulturalizma, makar kada je reč o koegzistenciji kultura u atmosferi koja ohrabruje njihov kritički dijalog i međusobno prožimanje. S tim u vezi, danas je moguće govoriti i o "transkulturnoj perspektivi”, odnosno o "kritičkom multikulturalizmu", u kojoj pojedinci nisu samo kulturno senzitivni prema različitim kulturama, već su aktivni, angažovani i obogaćeni iskustvom stupanja u interakciju sa drugim kulturama. Drugim rečima, tvrdi se da socijalni radnici moraju prevazići multikulturalizam u korist interkulturalizma.

U razmatranju evolucije multikulturalizma i interkulturalizma u praksi socijalnog rada korisno je istražiti i poreklo same profesije socijalnog radnika. Ona se pojavljuje iz potrebe za odgovorom na rastuće društvene probleme, a pre svega na siromaštvo, koji su (bili) u vezi sa industrijalizacijom, urbanizacijom i imigracijom sa kraja 19. veka (Stuart, 2008). Iz navedenih razloga, sami počeci socijalnog rada implicitno su usvojili pluralističke pristupe zasnovane na verovanju $\mathrm{u}$ jednaku vrednost nekih (iako dominantno belih) imigrantskih kultura. S druge strane, postojalo je i uverenje da će imigrantima "biti bolje" ako napuste svoju kulturu i postanu asimilovani ili ako se adaptiraju na novu kulturu "lonca za pretapanje". Tek nakon Pokreta za građanska prava iz 1960-ih godina dolazi do obnove interesovanja za kulturne razlike u pogledu boje kože, etniciteta i religije, a zatim i u vezi sa rodom, seksualnom orijentacijom itd., što se zatim prenosi i u doktrine kulturno kompetentnog socijalnog rada.

Koncepti multikulturalizma i interkulturalizma su složeni i ispunjeni kontroverzama $u$ vezi sa identitetom, prihvatanjem razlika, individualnim pravima 
i tome slično. Međutim, za socijalne radnike su multikulturalizam i interkulturalizam realnosti unutar kojih se obavlja profesija socijalnog rada. Oni su i činjenica koja nudi prilike za lični i profesionalni razvoj zato što socijalni radnici koji obavljaju svoju praksu među zajednicama koje čine kulturnu manjinu u nekom društvu moraju da razviju razumevanje za osnove određenih "strahova" ili nepoverenja koji postoje među pripadnicima kulturne većine. Zatim, oni moraju da razumeju i lične ambicije i aspiracije individua koje pripadaju manjinskim i marginalizovanim grupama, kao i da razumeju odlike njihovog simboličkog izražavanja (a posebno jezika). Konačno, neophodno je da socijalni radnici razumeju i politički kontekst i potencijalne oblasti aktivizma koji podstiče komunikaciju i kooperaciju. Da bi ovo bilo moguće, neophodno je upoznati se sa konceptom duboke kulture i interkulturnog učenja.

\section{DUBOKA KULTURA I INTERKULTURNO UČENJE KAO PREDUSLOV KULTURNO KOMPETENTNIH PRAKSI}

Duboka kultura se odnosi na nesvesna značenja, vrednosti, norme i skrivene pretpostavke koje nam omogućavaju da interpretiramo svoja iskustva tokom interakcije sa drugim ljudima (Shaules, 2007). Ova zajednička značenja zatim stvaraju okvir koji funkcioniše kao polazna osnova za naš osećaj šta znači biti čovek, šta čini normalno ponašanje, kako napraviti moralne ili etičke izbore itd. Duboka kultura obično funkcioniše na osnovu intuitivne svesti, tj. nje obično nismo svesni sve do situacije u kojoj moramo da stupimo u interakciju sa ljudima koji imaju drugačije kulturne pretpostavke. Drugim rečima, ako su naše telo i biološke sklonosti naš "hardver", onda je duboka kultura naš operativni sistem ili "softver" - stečeni okvir za percepciju, interpretaciju i rasuđivanje. Dakle, ona se ne odnosi na konkretna ponašanja, već na vrednosti i pretpostavke koje su u osnovi konkretnih ponašanja, npr. na različite kulturne pretpostavke o ulogama muškaraca i žena, različite orijentacije u vezi sa vremenom ili identitetom ("kolektivni" ili "individualni" identiteti), različito moralno ili etičko ponašanje itd. Kulturne razlike na ovom "dubokom" nivou predstavljaju najveći izazov po interkulturno učenje, a samim tim i po kulturno kompetentne prakse.

Duboka kultura se može objasniti metaforom "programiranja" zato što individue tokom odrastanja integrišu kulturne obrasce iz svog okruženja u svoje kognitivne i bihevioralne sklonosti (Shaules, 2010). Iz navedenih razloga ona funkcioniše poput mreža značenja u našem mozgu, iako je evidentna i na makro (ili meta) nivou, tj. reflektuje se u društvenim praksama zajednice. Zbog toga u izučavanju duboke kulture na empirijski način nije dovoljno pogledati jedino funkcionisanje našeg uma, već i obrasce interakcije među ljudima u društvenim zajednicama.

Još je Edvard Hol prepoznao dublju ili skrivenu stranu interkulturnog iskustva (Hall, 1959; 1966) i pisao je o tome da se Frojd pozivao na antropologiju kako bi pronašao podršku za svoje ideje, a da su antropolozi koristili teorije psihoanalize 
kako bi formulisali teorije kulture koje su adekvatn(ij)e. Jedna od tih pozajmljenih teorija zasnovana je na analogiji sa santom leda, gde kultura postoji na dva nivoa - "evidentna kultura, koja je vidljiva i koju je lako opisati, i skrivena kultura, koja nije vidljiva i predstavlja teškoću čak i obučenom posmatraču" (Hall, 1959: 85). Hol ističe da se ubrzo ova teorija pokazala neadekvatnom i da je Klakhon počeo da govori o eksplicitnoj i implicitnoj kulturi (vidi npr. Kluckhohn, 1949; Kroeber \& Kluckhohn, 1952). Eksplicitnu čine stvari o kojima može konkretno da se priča, poput pravnog sistema, a implicitnu sačinjavaju osećanja i sve ono što se uzima zdravo za gotovo i čega najčešće nismo svesni. Zato se implicitna kultura može nazvati i njenom "skrivenom dimenzijom".

Etnografske studije nam takođe ukazuju na činjenicu da ljudi u svim kulturama imaju snažan osećaj o tome kakav je svet zapravo, tako da ne čudi što se uvek iznenade kad otkriju da je "stvarnost" izgrađena na određenim pretpostavkama koje su zajedničke za pripadnike iste kulture (vidi npr. Brown, 1991). Te kulturne pretpostavke su apstraktni, organizovani, opšti koncepti koji prožimaju pogled na svet i ponašanje individua i egzistencijalne su u smislu što definišu ono što je "stvarno" i definišu prirodu te stvarnosti za pripadnike kulture. Njih najčešće ne artikulišemo na (svako)dnevnom nivou, tako da teško možemo da zamislimo njihove alternative sve dok nam se ne skrene pažnja na drugačije kulturne obrasce ili dok se naši ne dovedu u pitanje.

S druge strane, teoretičari poput Makluana su 1960-ih godina tvrdili da svet postaje "globalno selo" u kojem se ukidaju prostor i vreme i da se ljudi se prilagođavaju globalnom okruženju kao da je u pitanju njihovo "malo" mesto za život (McLuhan, 1962). Međutim, koncept duboke kulture dovodi ove vrste pretpostavki u pitanje jer čak i u (globalnom) selu postoje predrasude, sukobi, diskriminacija i nejednakost. Intenzivniji kontakt sa mnogim kulturama ne vodi uvek u harmoniju, već može odvesti i u začarani krug nerazumevanja i agresivnosti. Iako ljudi širom sveta dele mnoge proizvode i popularnu kulturu, različiti predmeti mogu nositi različita značenja: hamburger je statusna hrana za jedne, ali i simbol ekonomskog imperijalizma za druge (Shaules, 2007). Iako masovni mediji "dovode" kulturne razlike u naše domove, ovo može da bude veoma plitko iskustvo koje ne utiče na naš pogled na svet. Naime, ta površna interkulturna iskustva putem sredstava masovne komunikacije dodaju se na već postojeće kategorije značenja i samim tim ne (moraju da) predstavljaju pretnju po okvire duboke kulture, odnosno skrivenih vrednosti i kulturnih pretpostavki.

Slično tome, $i$ istraživači društvenih mreža tvrde da nove zajednice $u$ kiberprostoru približavaju različite ljude i stvaraju nove virtuelne zajednice (npr. Wellman, 1999). Međutim, akteri i u okvirima kompjuterski posredovane komunikacije neretko odabiraju da stupaju u interakciju samo sa onim individuama

Više o Holovom uticaju na izučavanje interkulturne komunikacije vidi u Rogers, Hart, and Miike, 2002. Veliki uticaj na Holovu karijeru ostavili su boazovski kulturni relativizam, lingvistički relativizam, Frojdova teorija, ali i etologija, koje (uz izuzetak etologije) jedan od koautora kritikuje u nekim publikacijama (npr. Škorić, 2004a; 2010: 411-413; 2013), ali to ne znači da su sve Holove ideje neprihvatljive. 
koje osnažuju njihove poglede na svet. Sa uvećanim brojem međusobno izolovanih grupa koje same sebe definišu na osnovu grupa kojima se protive, razlike i netolerancija se mogu uvećati, a ne smanjiti. Možda i zbog toga nije došlo do smanjenog broja interkulturnih sukoba, uprkos globalizaciji, lakšem pristupu informacijama, uvećanju obrazovanja i tome slično. Uz to, zbog fenomena regionalizacije i glokalizacije, globalizovani mediji ne stvaraju globalizovane zajednice na automatski ili neposredni način (Škorić i Kišjuhas 2012b).

Zatim, činjenica je da u savremenom društvu dolazi do sve češćih kontakata licem u lice sa ljudima različitog kulturnog, društvenog, religijskog i etničkog porekla. Tipičan primer za to jeste porast broja turista, odnosno činjenica da turizam nije više aktivnost rezervisana za elitu, kao i porast broja ljudi koji žive i rade u inostranstvu. S druge strane, lakoća sa kojom se putuje može dovesti do trivijalizacije turističkog iskustva, kao npr. kada se država ili region redukuju na spisak hramova ili spomenika koji se "moraju videti” u formi izolovanog turističkog aranžmana. Da bi se dogodilo istinsko, "duboko" kulturno učenje, neophodno je mnogo više od kratkog putovanja u inostranstvo ili od upoznavanja nekog pripadnika druge kulture.

Dakle, globalizacija uvećava broj ljudi koji prelaze nacionalne i kulturne granice, ali ona menja i način na koji ljudi stupaju u interakciju sa ljudima iz drugih nacionalnih i kulturnih zajednica (npr. Giddens, 2000). Uprkos naglašavanju tema kao što su multikulturalizam i interkulturni kontakt, ne smemo da izgubimo iz vida kako je globalizacija uvećala $i$ našu sposobnost da izbegnemo dublja interkulturna iskustva. Na primer, mnoge individue koje žive i rade u inostranstvu stvaraju prijateljstva jedino sa strancima, a ne sa lokalnim stanovništvom. Globalizovani svet jeste uvećao broj ljudi koji imaju raznovrsne interkulturne kontakte, od razmena elektronske pošte, preko turizma, sve do studiranja i rada u inostranstvu, ali ova iskustva postoje na kontinuumu od površnog do angažovanijeg i dubljeg. Površni kontakti duž kulturnih granica mogu maskirati mnoge dublje i suptilnije kulturne razlike koje neretko stvaraju interkulturne nesporazume, uključujući tu i osnaživanje izolacije i sukoba.

Proces reagovanja na adaptivne zahteve koji rezultiraju iz interakcije sa novim kulturnim okruženjem predstavlja interkulturno učenje (Feng, Byram, \& Fleming, 2009). Adaptiranje na život u novom kulturnom okruženju ili kulturno učenje može biti veoma snažno iskustvo, a istovremeno su ishodi kulturnog učenja veoma teški za predviđanje i objašnjenje. Stupanje u novo okruženje je izazov po kulturno učenje i po adaptaciju, a "dublja" adaptacija na novo okruženje odnosi se na novo promišljanje sopstvenih verovanja, vrednosti i pretpostavki. Promene u ponašanju mogu biti praćene i promenom u načinu na koji posmatramo svet, što čini istinsko interkulturno učenje (Shaules, 2007).

Kada je reč o perspektivama o interkulturnom učenju, ovim temama su se na makro nivou bavili antropolozi i sociolozi, obično u kontekstu procesa kao što su akulturacija, asimilacija, integracija ili marginalnost. Prema ovoj perspektivi, akulturacija se posmatra kao grupni fenomen u kojem individue koje pripadaju 
pojedinim društvenim kategorijama prolaze kroz proces asimilacije ili (p)ostaju u stanju marginalnosti. Na mikro nivou, obično se naglašavaju interni procesi promene $\mathrm{u}$ individuama koje stupaju u «stresnu» interakciju sa novim okruženjem, uz konceptualizaciju fenomena kao što su suočavanje, prilagođavanje, kulturni šok, adaptacija itd. Na primer, kroskulturnu adaptaciju moguće je odrediti kao dinamički proces u kojem individue u novom kulturnom okruženju uspostavljaju i održavaju relativno stabilne, recipročne i funkcionalne odnose sa tim okruženjem.

$\mathrm{S}$ tim u vezi, moguće je govoriti i o interkulturnom učenju kao o proživljenom iskustvu rukovođenja ili baratanja nepoznatim kulturnim okruženjem. Uz to, ovaj termin može da se odnosi i na imigrante koji duži vremenski period žive u tom okruženju, ali i na turiste koji su u tom okruženju kraće vreme. Učenje duboke kulture ili interkulturno učenje može da bude površinsko ili duboko, a tri ključna elementa svakog učenja duboke kulture najčešće su: otpor, prihvatanje i adaptacija (Shaules, 2010). Interkulturno učenje počiva na opisanoj «programiranosti» uma koje je moguće označiti kao duboku kulturu o koju se oslanjamo u našim svakodnevnim interakcijama, komunikaciji i pri interpretaciji tuđih akcija. Kulturne razlike na ovom «dubokom» nivou predstavljaju najveći izazov po interkulturno učenje, a samim tim i po kulturno kompetentne prakse u socijalnom radu.

\section{KULTURNA KOMPETENTNOST}

Kao što je rečeno, problem kulturne kompetentnosti reflektuje vrlo blisku vezu između antropologije i socijalnog rada. Ne postoji opšteprihvaćena definicija kulturne kompetentnosti (ili interkulturne ili kroskulturne kompetentnosti), a najjednostavnije rečeno u pitanju je sposobnost da se efikasno stupa u interakciju sa ljudima različitih kultura (ponekad se pod time podrazumeva i sposobnost komunikacije sa ljudima raznih socioekonomskih statusa, seksualnog opredeljenja itd.). ${ }^{2}$ Antropologija je nauka koja se najdirektnije bavi problemom kulture i ona najjasnije demonstrira koje su potencijalne posledice nerazumevanja drugih kultura. Kada se radi i o konceptu kulturne kompetentnosti, njegova direktna preteča takođe je Edvard Hol (Hall, 1959, 1966), koji je skrenuo pažnju na tzv. kulturno programiranje kojeg nismo svesni, a o čemu je bilo reči u kontekstu duboke kulture.

Puno društvenih problema ima svoj koren u kulturi, tako da je postalo evidentno da praksa socijalnog rada u multikulturnim sredinama i te kako zavisi (i) od razumevanja drug(ačij)ih kultura i da je zbog toga potrebno razvijati kulturnu kompetentnost. Dakle, vrlo je važno shvatiti razlike u ponašanju, načinu mišljenja, pretpostavkama i vrednostima u kulturno mešovitim okruženjima. Ipak, kulturna

2 Ovi pojmovi se često koriste naizmenično, ali moguće je ponuditi preciznija značenja za svaki od njih. „Kroskulturno“ se odnosi na bilo koje poređenje kulturnih razlika ili na situacije u kojima te razlike postoje. „Interkulturno“ se obično dodaje terminima „komunikacija“ ili „odnosi“ i tiče se stvarne interakcije između ljudi različitih kultura (vidi npr. Moule, 2012: 10-11; Leeds-Hurwitz, 2010). 
samosvest nije uvek jednostavna za problematizaciju od strane individua, zato što je kultura internalizovana (između ostalog i) kroz obrasce mišljenja i ponašanja za koje se veruje da su «prirodni», «ispravni» $\mathrm{i}$ «dobri», a neretko $\mathrm{i}$ «superiorni» $\mathrm{u}$ odnosu na druge. Takođe, ljudi često greše i zato što kulturne ili društvene faktore interpretiraju kao karakteristike individualne ličnosti.

Najveći broj nesporazuma u interakcijama licem u lice potiče upravo iz domena implicitne ili subjektivne kulture koju čine psihološka obeležja poput vrednosti, pretpostavki i obrazaca mišljenja. Objektivnu kulturu sačinjavaju institucije i artefakti kulture poput ekonomskog sistema, običaja, političkih struktura i procesa, umetnosti itd. Ona je daleko više izučavana, lakša je za analizu i njome se bave brojne društvene nauke, dok se subjektivnom najviše bavi antropologija, iako takođe manje nego objektivnom. Zbog toga je osnovna teškoća kroskulturne interakcije neprepoznavanje ili nerazumevanje relevantnih kulturnih razlika, što je obično posledica stereotipa i predrasuda, odnosno verovanja da su nečije vrednosti prirodne i da treba da budu univerzalne (vidi npr. Škorić 2006).

Kada se radi o kulturnim vrednostima, one se odnose na poželjnost određenih akcija ili stavova među pripadnicima kulture. Vrednosti takođe po sebi nisu ponašanje, već su u pitanju procesi koji rukovode onim što ljudi u određenoj kulturi smatraju da treba da se radi - one nude kriterijume koji rukovode ponašanjem jer poseduju sadržaj i emociju i doprinose društvenoj stvarnosti (vidi Śkorić 2010: 42-58). Obično nije moguće da se, na primer, socijalni radnik u potpunosti uživi u ulogu pripadnika druge kulture, tako da se može govoriti o «trećoj kulturi» koja je zasnovana na proširenom kroskulturnom razumevanju. ${ }^{3}$ Prvi korak u tome jeste znanje o pretpostavkama i vrednostima na kojima počiva sopstveno ponašanje jer na taj način osoba može sistematski da kontrastira ove pretpostavke i vrednosti sa onima iz druge kulture koju pokušava da razume i da otkrije oblasti kulturnih razlika koje su relevantne za neku određenu situaciju. To znanje se može koristiti radi empatije i stvaranja zajedničkog terena koji je neophodan za uspešnu interkulturnu komunikaciju i interkulturno učenje (Feng, Byram, \& Fleming, 2009).

\section{KULTURNO KOMPETENTNA PRAKSA}

$\mathrm{Na}$ osnovu svega navedenog, jasno je da kulturnu kompetentnost čine usluge, podrške i neke druge vrste pomoći koje se nude na način koji odgovara verovanjima, interpersonalnom stilu komunikacije, stavovima, jeziku i ponašanju korisnika usluga na način koji obezbeđuje da korisnici maksimalno participiraju u nekom programu. Nešto jasnije rečeno, kulturna kompetentnost je zapravo kompetentnost

\footnotetext{
Ovde se ne misli na „treću kulturu“, odnosno Treću kulturu (Brockman, 1995), koja je nastala pod uticajem "dve kulture" (Snow, 1959/1964). "Dve kulture" govore o podeli na dve naučne kulture koje karakterišu prirodne nauke i humanističke discipline, što je ozbiljan problem koji je nastavljen i naknadnim "naučnim ratovima" (vidi Škorić 2010: 485-546). Treća kultura u Brokmanovom kontekstu označava direktno komuniciranje naučnika sa javnošću.
} 
u sticanju kulturno relevantnih razumevanja problema (kulturnih) manjina koja se mogu upotrebiti radi pružanja kulturno prikladnih intervencija u socijalnom radu. Dakle, u okviru socijalnog rada kulturna kompetentnost se ne odnosi samo na poznavanje druge kulture, nego i manjina i manjinskih životnih stilova unutar iste kulture.

Kulturno kompetentna praksa predstavlja pokušaj da se kulturna kompetentnost integriše u praksu socijalnog rada i tiče se individua, profesionalnog obrazovanja, modela prakse, ali i sistemskih nivoa. U tom smislu ona je deo kontinuuma društvene sposobnosti i razvoja ličnosti i obuhvata individuin osećaj samopouzdanja, kulturni identitet koji je u vezi sa kulturom porekla i kulturnim kontekstom, i znanje, razumevanje i internalizaciju osnovnih verovanja kulture. U ovom kontekstu, i sa stanovišta prakse kulturna kompetentnost se može shvatiti i kao razvoj akademske i profesionalne ekspertize i veština u radu sa kulturno različitim klijentima (Magala, 2005). Zato je početna tačka kulturna svesnost, a ona se razvija prvenstveno preko istraživanja sopstvenog etničkog identiteta, kulturne pozadine i kontakta sa klijentima različitih etničkih pripadnosti. Pored toga, socijalni radnik mora da razvije i perspektivu sticanja znanja i skup veština kako bi radio u multikulturnom okruženju. Iz toga sledi da sticanje znanja nosi sa sobom činjenice i principe koji služe kao vodilje za najbolje rešavanje problema i kulturne ili etničke dimenzije određenog klijenta. Razvoj veština primenjuje sticanje znanja na stvarnu praksu sa klijentima iz kulturno kompetentne perspektive. I konačno, kulturno kompetentna praksa mora da teži konstantnom otkrivanju novih činjenica o klijentima iz multikulturnog okruženja preko procesa učenja (APA, 2003, 2008; Moule, 2012; NASW, 2001; 2007).

Iako se u kontekstu kulturno kompetentne prakse najviše pominju rasa $\mathrm{i}$ etnicitet, ona bi trebalo da inkorporira različita istorijska, politička, socioekonomska, psihofizička, duhovna i ekološka znanja i dimenzije stvarnosti, njihove međusobne interakcije i uticaj na individue i grupe. U tom smislu kulturu je potrebno shvatiti u najširem smislu, tako da uključuje rasu, etnicitet, rod i seksualnu orijentaciju, ali i druge dimenzije individualnih ili grupnih iskustava koja su relevantna za njihovo razumevanje sveta i sebe samih. Zato kulturno kompetentna praksa mora da bude svesna svog konteksta, jer prilagođavanje dimenzija kulturne kompetentnosti, kako bi one bile u skladu sa perspektivama i pogledima na svet socijalnog radnika i klijenta, predstavlja jednu od najvažnijih dimenzija procesa pružanja podrške ili pomoći (Henderson, Nadkarni, \& Erickson Cornish, 2010; Lee, 2013; Lee \& Park, 2013).

Moguće je govoriti o tri nivoa kulturno kompetentne prakse. Prvi je nivo praktičara, i na tom nivou socijalni radnik mora da poznaje problematiku vrednosti, kulturno nasleđe, razlike u vrednosnim sistemima i da bude svestan kulture drugih, prvenstveno klijenata (npr. Lee, 2013). Drugi nivo je nivo organizacija socijalnog rada, zato što socijalni radnici treba da budu obučeni u veštinama koje su neophodne za prakse koje su osetljive na razlike, a u organizacijskoj strukturi i sprovođenju programa treba da se promovišu multikulturna svest i funkcionisanje 
(npr. Tyler, 2001). I konačno, postoji nivo zajednice koji se bavi promovisanjem konteksta pluralizma, različitosti, kroskulturne interakcije i društvene pravde (npr. Lorenz, 1998).

Pored ove distinkcije kulturne kompetentnosti postoje i njene mikro, mezo i makro dimenzije. Mikro kulturna kompetentnost uključuje klijenta i socijalnog radnika, mezo uključuje organizacioni nivo i na taj način se utvrđuje da li neka organizacija poseduje kulturno kompetentni sistem brige i nege, dok se makro odnosi na pokušaje većih sistema da se bave pitanjima i programima kulturne kompetentnosti.

\section{KULTURNO KOMPETENTNI SOCIJALNI RADNIK}

Kada se radi o socijalnom radu u multikulturnom okruženju vrlo je važno imati na umu da socijalni radnik mora ne samo da razume kulturne razlike koje se reflektuju u pogledima na svet, već i sociopolitičke dimenzije kulturno kompetentne nege. To je zato što se socijalni rad bavi individuama, grupama, zajednicama, institucijama, ali i javnom politikom, tako da su ciljne grupe mnogo šire nego što je to slučaj u psihologiji ili psihijatriji. Samim tim, praksa socijalnog rada u multikulturnom okruženju inkorporira i dimenzije rase, etniciteta, roda, seksualne orijentacije itd. ${ }^{4}$ Zbog toga on zavisi od nekoliko stvari. Neizostavna je kreativnost radi premošćavanja razlika u percepciji, komunikaciji i implementiranju vrednosti i verovanja, jer bez nje ne bi bilo ni kulturnih varijeteta (vidi npr. Škorić i Tomašević 2011; Škorić i Kišjuhas 2012a za prikaz kreativnosti iz perspektive društvenih mreža), ali isto važi i za kritičku svest, naročito kada se radi o (raz) otkrivanju ideologija i metodologija koje se nalaze "iza" ovih razlika (Škorić i Kišjuhas 2014, 2015). I konačno, moralna autonomija je nešto što omogućava kroskulturno kompetentnim individuama da donesu najbolju moguću odluku (Magala, 2005).

Cilj socijalnog rada jeste da poboljša blagostanje i nivo funkcionisanja ljudi i da stvori pozitivnu društvenu promenu putem poboljšanja društvenih uslova $i$ stvaranja humanijih praksi i politika za osetljive i ranjive populacije. U multikulturnom kontekstu socijalni radnik bi trebalo da poseduje makar osnovnu kulturnu senzitivnost, što bi značilo da treba da bude osetljiv ili svestan da postoje razni životni stilovi i da ih uvažava, a ove kompetencije najlakše se razvijaju prilikom susreta sa stranim kulturama. Pored neke opšte svesti o kulturnim razlikama neophodno je da bude sposoban (ili osposobljen) da o njima razmišlja bez pristrasnosti, predrasuda ili stereotipa, a to se u praksi postiže pre svega komunikacijom sa korisnicima. Takođe je bitno da postoji i želja da se uči o drugima i da se ti drugi razumeju ili shvate, čime može da se prevaziđe puka subjektivna percepcija i interpretacija ponašanja drugih ljudi, naročito marginalizovanih, stigmatizovanih i (u kulturnom smislu) nepoznatih grupa.

\footnotetext{
Ne misli se na to da rasa zaista postoji u biološkom smislu, nego samo da je bitna u sociološkom (vidi Škorić 2004: 295n28; Škorić i Kišjuhas 2015).
} 
Zato je nužno da socijalni radnik tokom obrazovanja stekne određeni korpus kulturnih/antropoloških znanja o čovečanstvu kao celini, kao i o individui, porodici, grupi ili zajednici o kojoj se konkretno radi u određenom slučaju. Pored univerzalnih ljudskih karakteristika vrlo su važne i interkulturne razlike $u$ običajima, verovanjima, vrednosnom sistemu i slično, jer je često potrebno ponuditi tretman i procenu koji su kulturno relevantni za korisnike. Pored kulturnog znanja nije zanemarljiva ni kulturna empatija, zato što u odnosu sa korisnikom nisu dovoljne samo činjenične informacije o njegovoj kulturi kako bi se ostvario smislen i adekvatan kontakt. Neizostavna je i sposobnost razumevanja na emocionalnom nivou koje se odvija iz kulturne perspektive korisnika, jer u suprotnom će uvek postojati jaz u razumevanju i socijalni radnik neće biti u stanju da razume emocionalno iskustvo korisnika i da u njemu učestvuje. Dakle, socijalni radnik mora da se trudi da u svoj rad inkorporira kulturne atribute - mora uzeti u obzir kulturne pozadine korisnika i samog sebe, ali i kulturne aspekte okruženja u kojem se odvijaju interakcije kako bi usluga koju pruža bila (i) kulturno prikladna (Arasaratnam \& Doerfel, 2005; Spitzberg, 1989).

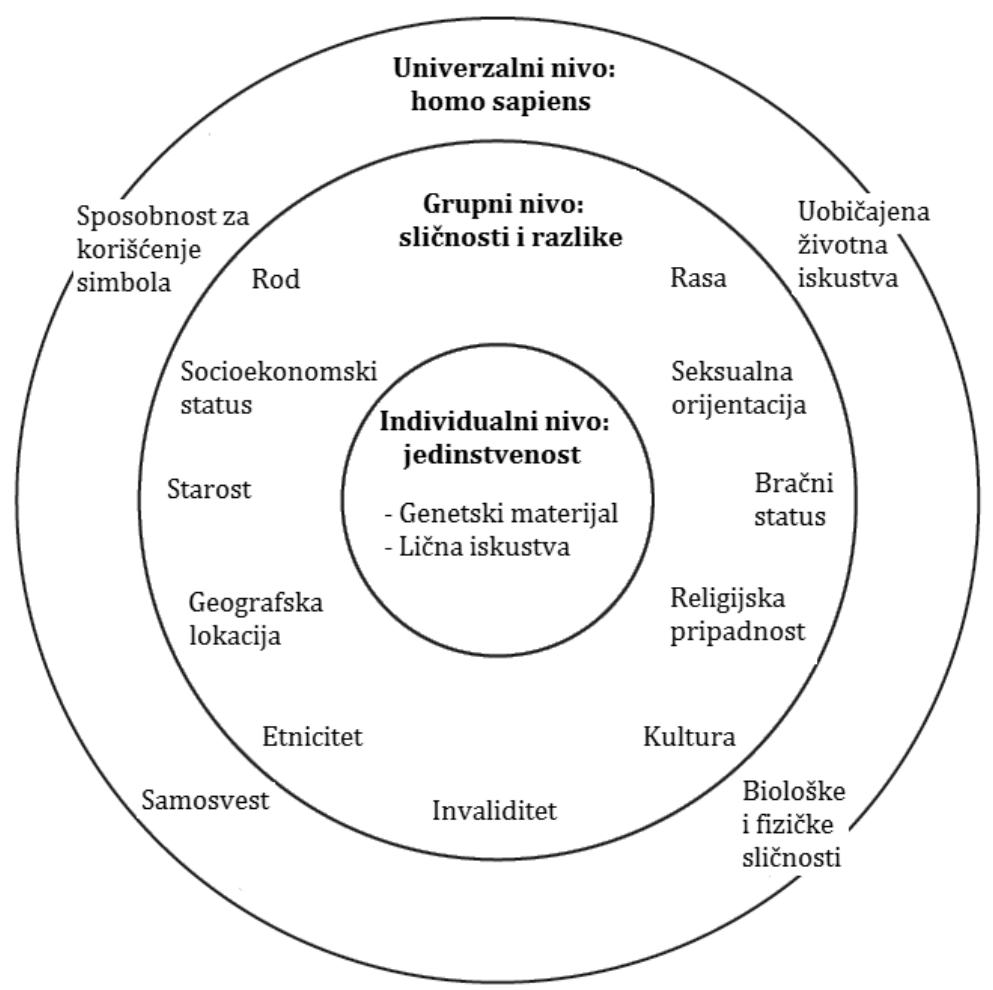

Tripartitni razvoj ličnog identiteta (prema Sue 2006: 17) 
Kao zaključak mogu da se navedu četiri osnovne karakteristike koje socijalni radnik mora da poseduje kako bi mogao da se smatra za profesionalca koji je kulturno kompetentan (Sue, 2006). (1) U pitanju je osoba koja je uvek svesna sopstvenih pretpostavki o ljudskom ponašanju, vrednostima, pristrasnostima, ali i ličnim ograničenjima, tj. koja je svesna sopstvene_duboke kulture. To znači da bez problematizovanja sopstvenog pogleda na svet socijalni radnik vrlo lako može da stekne utisak da je on zajednički za sve grupe, što je vrlo opasno, zato što se na taj način nameću kulturno specifične definicije društvene stvarnosti, kao i kulturno partikularni vrednosni sistem. Sopstveno (pre)ispitivanje je vrlo teško zbog snažnog emocionalnog uticaja stavova, verovanja i osećanja koji su povezani sa kulturnim razlikama koje mogu vrlo lako da dovedu do nenamer(ava)nog rasizma, seksizma, ejdžizma i slično.

(2) Kulturno kompetentni socijalni radnik bi trebalo da aktivno pokušava da razume pogled na svet svojih klijenata koji dolaze iz drugih kulturnih miljea. Kao što slika jasno pokazuje, pored brojnih sličnosti koje delimo kao pripadnici iste vrste za zajedničkom evolucionom prošlošću, grupno pripadništvo u izvesnoj meri takođe utiče na naše međusobne razlike. To znači da je pogled na svet pod velikim uticajem $i$ naših životnih iskustava, a uopšteno posmatrano možemo da ga opišemo kao način na koji dajemo značenje svetu oko nas (Kearney, 1975). U tom smislu on nije samo puki skup naših brojnih dimenzija ličnosti, već takođe i utiče na to kako mislimo, definišemo stvarnost, donosimo odluke i ponašamo se. Za socijalni rad od ogromne važnosti jeste činjenica da socijalni radnik može da deli pogled na svet sa svojim klijentima. On ne mora da bude identičan, ali trebalo bi da se drugi pogledi na svet prihvataju otvoreno i bez ikakvih osuda i vrednosnih procena. Zato se može govoriti o kulturnom preuzimanju uloga koje predstavlja neku vrstu kognitivne empatije, a koja je opet drugačija od afektivne empatije (Watt, 2007). Prilikom kulturnog preuzimanja uloga socijalni radnik stiče praktična znanja koja se tiču obima i prirode kulturne pozadine svog klijenta, njegovih životnih iskustava, aspiracija itd. Kognitivna empatija je vrlo važna zato što u sebi sadrži razumevanje o tome u kakvom su odnosu socijalne usluge sa širim sociopolitičkim sistemom sa kojima se manjine (najšire shvaćene) svakodnevno susreću, a može se govoriti i o inkluzivnoj kulturnoj empatiji (Pedersen, Crethar, \& Carlson, 2008).

(3) $\mathrm{Na}$ osnovu ovih znanja socijalni radnik bi trebalo aktivno da razvija $\mathrm{i}$ upražnjava strategije i veštine rada sa klijentima koje su prikladne, relevantne i senzitivne. Moraju se razvijati prikladne i efikasne strategije pomaganja, podučavanja, komunikacije i intervenisanja prilikom rada u multikulturnoj sredini, a to se najbolje i najlakše postiže upotrebom načina intervenisanja i definisanjem ciljeva koji su konzistentni sa životnim iskustvima i kulturnim vrednostima klijenta. Dakle, socijalni radnik ne sme da pretpostavi da njegovi klijenti imaju slično kulturno nasleđe koje on sam ima i da su isti pristupi jednako efikasni sa svim klijentima (Lum, 2011). 
(4) I konačno, on bi trebalo da bude u stanju da razume načine na koje organizacione $\mathrm{i}$ institucionalne sile mogu da unaprede ili unazade razvoj kulturnih kompetencija. Nije retka situacija u kojoj organizacije koje pružaju socijalne usluge aktivno opstruiraju multikulturni pristup, zato što, na primer, funkcionišu sa monokulturnim socijalnim politikama i praksama i zato je potrebno razvijati nova pravila, regulacije, politike, prakse i strukture unutar organizacija koje jačaju multikulturalnost. Kako bi se neka organizacija razvijala multikulturno potrebno je da se situacija posmatra iz perspektive socijalne pravde (npr. Ferguson, Lavalette, \& Whitmore, 2005), da postoji ubeđenje da nejednakosti u organizacijama ne nastaju prvenstveno zbog loše komunikacije, nedostatka znanja, lošeg rukovođenja itd., već zbog monopola moći i da postoji pretpostavka da je konflikt neizbežan i da nije nužno štetan (Collins, 1975).

Socijalni rad obično visoko vrednuje multikulturalizam i interkulturalizam, odnosno promoviše kulturni diverzitet i koristi kulturnu kompetentnost kao veoma važan alat socijalnog rada. Oblasti socijalne politike i socijalne zaštite moraju razumeti i poštovati različite kulture, kao što moraju da ponude kulturno relevantne programe i usluge. Različiti etički kodeksi i slični vodiči za socijalne radnike u mnogim zemljama sveta obuhvataju i principe prema kojima socijalni radnici moraju posedovati bazu znanja o kulturi svojih korisnika, odnosno demonstrirati kompetentnost u pružanju usluga koje su osetljive na kulturne razlike. Iz navedenih razloga, neophodno je da socijalni radnici ohrabre interaktivne društvene procese između većinskih i manjinskih populacija, odnosno populacija koje su dominantne i onih koje zahtevaju prihvatanje i priznanje.

Izgradnja kulturne kompetentnosti je primarni cilj za multikulturnu (i interkulturnu) praksu socijalnog rada. Uzimajući u obzir koncepte duboke kulture i interkulturnog učenja, kulturna kompetentnost označava integraciju i transformaciju znanja o individuama i grupama u specifične standarde, javne i socijalne politike, socijalne prakse i stavove koji se koriste u prikladnim kulturnim okruženjima kako bi se uvećao kvalitet usluga socijalne zaštite. Ovo podrazumeva i učenje novih obrazaca ponašanja i njihovu efikasnu primenu na adekvatne kontekste i populacije. Oni istovremeno pozivaju i na veću svest socijalnih radnika o uticaju koji programi socijalne politike mogu imati na različite kulturne grupe. $\mathrm{Na}$ ovaj način socijalni radnici postaju svesni sopstvenih pretpostavki, vrednosti, pristrasnosti i predrasuda o ljudskom ponašanju, koje mogu da osujete efikasni socijalni rad. Uz razumevanje fenomena duboke kulture, kao i uz aktivni angažman $\mathrm{u}$ interkulturnom učenju, socijalni radnici moraju dobro poznavati fenomene kulture, klase, rase, etniciteta itd., kao i njihov odnos prema varijablama moći i društvene (ne)jednakosti. Konačno, neophodno je razumeti i poglede na svet korisnika usluga socijalne zaštite koji pripadaju drugačijim kulturama. 


\section{REZIME}

Socijalni rad izučava i osnažuje društvene interakcije među ljudima koje utiču na njihove sposobnosti da ostvare svoje aspiracije i vrednosti, zbog čega je koncept kulturne kompetentnosti od izuzetnog značaja i za akademsku disciplinu i za profesiju socijalnog rada. Bavljenje socijalnim radom zahteva i suprotstavljanje diskriminaciji i represiji koje često trpe korisnici usluga socijalne zaštite, tako da je važno prepoznati manjinske, diskriminisane i marginalizovane pojedince u nekoj grupi i zajednici, odnosno u društvu ili u kulturi. U tom smislu, ovaj rad je posvećen problematici kulturne kompetentnosti u kontekstu socijalnog rada u multikulturnom okruženju. Multikulturalizam se kao politički pokret, ideologija i/ili socijalno-politička praksa suprotstavlja monokulturalizmu, odnosno normativnom kulturnom jedinstvu i kulturnoj homogenosti. U pitanju je i građansko i ljudsko pravo kulturnih grupa koje je ukorenjeno u ljudskom dostojanstvu i u fundamentalnoj jednakosti različitih kultura (uključujući tu i kulturne razlike koje se tiču rase, etniciteta, verske pripadnosti, veština i sposobnosti, roda, seksualnosti, ekonomskog i društvenog položaja itd.). Uz to, važna je i ideja interkulturalizma koja implicira kroskulturni dijalog i aktivno učenje umesto pasivnog prihvatanja multikulturalizma kao proste pluralnosti međusobno segregiranih i/ili izolovanih kultura.

Kao značajan koncept za razumevanje međuodnosa kulturne kompetentnosti i socijalnog rada izdvaja se koncept duboke kulture, kao i ideja o interkulturnom učenju kao preduslovu kulturno kompetentnih praksi. Duboka kultura predstavlja nesvesna značenja, vrednosti, norme i skrivene pretpostavke koje omogućavaju da interpretiramo svoja iskustva tokom interakcije sa drugim ljudima. Iz tih razloga, problematizovana je relevantnost duboke kulture u savremenom kontekstu učestalijeg kulturnog kontakta, novih društvenih mreža i zajednica, odnosno fenomena globalizacije.

Konačno, istaknuta je relevantnost kulturne kompetentnosti koja predstavlja sposobnost da se efikasno stupa u interakciju sa ljudima različitih kultura. Tvrdi se da praksa socijalnog rada u multikulturnim sredinama i te kako zavisi (i) od razumevanja drugačijih kultura zbog čega je neophodno razvijati kulturnu kompetentnost - shvatiti razlike u ponašanju, načinu mišljenja, pretpostavkama i vrednostima u kulturno mešovitim okruženjima. Veliki broj društvenih problema i nesporazuma u interakcijama potiče upravo iz domena implicitne ili duboke kulture, što ima posledice po kulturno kompetentni socijalni rad.

$\mathrm{Na}$ osnovu svega navedenog, tvrdi se da kulturnu kompetentnost čine usluge, podrške i neke druge vrste pomoći koje se nude na način koji odgovara verovanjima, interpersonalnom stilu komunikacije, stavovima, jeziku i ponašanju korisnika usluga. Dakle, kulturna kompetentnost je zapravo kompetentnost u sticanju kulturno relevantnih razumevanja problema (kulturnih) manjina koja se mogu upotrebiti radi pružanja kulturno prikladnih intervencija u socijalnom radu. Izlažu se tri nivoa kulturno kompetentne prakse: nivo praktičara, nivo organizacija socijalnog rada i nivo zajednice, uz mikro, mezo i makro dimenzije ove prakse. Zato je nužno da socijalni radnik tokom obrazovanja stekne određeni korpus kulturnih/antropoloških znanja o čovečanstvu kao celini, kao i da bude otvoren prema interkulturnom učenju o razlikama u običajima, verovanjima, vrednosnom sistemu itd. individua ili korisnika usluga. Drugim rečima, kulturno kompetentni socijalni radnik mora da razume interkulturne i sociopolitičke dimenzije sopstvene profesionalne prakse na kreativan, kritički i moralno autonoman način. 


\section{THE IMPORTANCE OF CULTURAL COMPETENCE FOR SOCIAL WORK}

\section{SUMMARY}

Social work studies and reinforces social interaction among people that affect their ability to achieve their aspirations and values. This is the reason why the concept of cultural competence is of great importance to the academic discipline and the profession of social work. Social work also demands an opposition to discrimination and repression of the social protection users, which is why it is crucial to recognize the minority, discriminated and marginalized individuals in a group and the community, and in a society or culture. In this sense, this paper is dedicated to the concept of cultural competence in the context of social work in a multicultural environment. Multiculturalism is a political movement, ideology and/or socio-political practice that opposes monoculturalism or normative cultural unity and cultural homogeneity. It is a civil and human right of cultural groups that is rooted in human dignity and the fundamental equality of different cultures (including the cultural differences regarding race, ethnicity, religion, skills and ability, gender, sexuality, economic and social status, etc.). In addition, the important idea of interculturalism implies crosscultural dialogue and active learning rather than passive acceptance of multiculturalism as a simple plurality of mutually segregated and/or isolated cultures.

As an important concept for understanding the relationship between cultural competence and social work stands the concept of deep culture, as well as the idea of intercultural learning as a prerequisite of a culturally competent practice. Deep culture represents unconscious meanings, values, norms and hidden assumptions that allow interpretations of our experiences during interactions with other people. For these reasons, we problematize the key relevance of cultural competence in the contemporary context of more frequent cultural contacts, new social networks and communities, and the phenomenon of globalization.

Finally, we highlight the relevance of cultural competence as an ability to effectively interact with people of different cultures. It is claimed that the practice of social work in multicultural environments strongly depends on the understanding of different cultures which makes it necessary to develop cultural competence - to understand the differences in behavior, ways of thinking, assumptions and values in the culturally mixed environments. A large number of social problems and misunderstandings in interactions follows from the domain of implicit or deep culture, which has implications for a culturally competent social work.

Based on these findings, it is argued that cultural competence is comprised of services, support and other forms of assistance that are offered in a way that matches the beliefs, interpersonal communication styles, attitudes, language and behavior of service users. Thus, cultural competence is actually a competence in acquiring culturally relevant understandings of (cultural) minority problems that can be used in odred to provide culturally appropriate interventions in social work. We offer three levels of culturally competent practices: the level of practitioners, the level of organization of social work and community level, with the micro, meso and macro dimensions of these practices. Therefore, it is necessary that, in the process of their education, social workers acquire a certain core of cultural/anthropological knowledge about humanity as a whole, and to be open to intercultural learning about the differences in customs, beliefs, value systems etc. of individuals and service users. In other words, culturally competent social worker must understand cross-cultural and sociopolitical dimensions of their own professional practice in a creative, critical and morally autonomous way.

Keywords: social work, multicultural/intercultural environment, deep culture, intercultural learning, cultural competence. 


\section{LITERATURA}

American Psychological Association (2003). Guidelines on multicultural education, training, research, practice, and organizational change for psychologists. American Psychologist, 58, 377-402.

American Psychological Association (2008). Report of the Task Force on the Implementation of the Multicultural Guidelines. Washington: Author.

Arasaratnam, L. A. \& M. L. Doerfel (2005). Intercultural communication competence: Identifying key components from multicultural perspectives. International Journal of Intercultural Relations, 29, 137-163.

Brockman, J. (1995). The Third Culture: Beyond the Scientific Revolution. New York: Simon \& Schuster.

Brown, D. E. (1991). Human Universals. New York: McGraw-Hill.

Collins, R. (1975). Conflict Sociology: Toward an Explanatory Science. New York: Academic Press.

Feng, A., M. Byram, \& M. Fleming (eds) (2009). Becoming Interculturally Competent through Education and Training. Bristol: Multilingual Matters.

Ferguson, I., M. Lavalette, \& E. Whitmore (eds) (2005). Globalisation, Global Justice and Social Work. London and New York: Routledge.

Giddens, A. (2000). Runaway World. London: Routledge.

Hall, E. T. (1959). The Silent Language. New York: Doubleday.

Hall, E. T. (1966). The Hidden Dimension. New York: Doubleday.

Henderson Metzger, L. L., L. I. Nadkarni, \& J. A. Erickson Cornish (2010). An overview of multicultural counseling competencies. In: J. A. Erickson Cornish, B. A. Schreier, L. I. Nadkarni, L. Henderson Metzger, \& E. R. Rodolfa (eds), Handbook of Multicultural Counseling Competencies (pp. 1-21). Hoboken: John Wiley \& Sons, Inc.

Kastoryano, R. (ed.) (2009). An Identity for Europe: The Relevance of Multiculturalism in EU Construction. New York: Palgrave Macmillan.

Kearney, M. (1975). World view theory and study. Annual Review of Anthropology, 4, 247-270.

Kirk, S. A. \& W. J. Reid (2002). Science and Social Work: A Critical Appraisal. New York: Columbia University Press.

Kirst-Ashman, K. K. (2008). Human Behavior, Communities, Organizations, and Groups in the Macro Social Environment: An Empowerment Approach, $2^{\text {nd }}$ Edition. Belmont: Thomson Brooks/Cole.

Kluckhohn, C. (1949). Mirror For Man: A Survey of Human Behavior and Social Attitudes. Greenwich: Fawcett Publications, Inc.

Kroeber, A. L. \& C. Kluckhohn (1952). Culture: A Critical Review of Concepts and Definitions. Cambridge: Papers of the Peabody Museum of American Archaeology and Ethnology 42 (1).

Laden, A. S. \& D. Owen (eds) (2007). Multiculturalism and Political Theory. Cambridge: Cambridge University Press.

Lee, C. C. (2013). The cross-cultural encounter: Meeting the challenge of culturally competent counseling. In: C. C. Lee (ed), Multicultural Issues in Counseling: New Approaches to Diversity, $4^{\text {th }}$ Edition (pp. 13-19). Alexandria: Wiley. 
Lee, C. C. \& D. Park (2013). A conceptual framework for counseling across cultures. In: C. C. Lee (ed), Multicultural Issues in Counseling: New Approaches to Diversity, $4^{\text {th }}$ Edition (pp. 3-12). Alexandria: Wiley.

Leeds-Hurwitz (2010). Writing the intellectual history of intercultural communication. In: T. K. Nakayama \& R. T. Halualani (eds), The Handbook of Critical Intercultural Communication (pp. 21-33). Madden: Wiley-Blackwell.

Lorenz, W. (1998). Social work, social policies and minorities in Europe. In: C. H. Williams, H. Soydan, \& M. R. D. Johnson (eds), Social Work and Minorities: European Perspectives (pp. 247-264). London and New York: Routledge.

Lum, D. (2011). Culturally Competent Practice: A Framework for Understanding Diverse Groups and Justice Issues, $4^{\text {th }}$ Edition. Belmont: Brooks/Cole.

Magala, S. (2005). Cross-cultural Competence. London nad New York: Routledge.

McLuhan, M. (1962). The Gutenberg Galaxy: The Making of Typographic Man. Toronto: University of Toronto Press.

Meer, N. \& T. Modood (2012). How does interculturalism contrast with multiculturalism? Journal of Intercultural Studies, 33, 175-196.

Moule, J. (2012). Cultural Competence: A Primer for Educators, Second Edition. Belmont: Wadsworth.

National Association of Social Workers (2001). NASW Standards for Cultural Competence in Social Work Practice. Washington: Author.

National Multicultural Advisory Council (1999). Australian Multiculturalism for a New Century: Towards Inclusiveness. Canberra: NMAC.

National Association of Social Workers (2007). Indicators for the Achievement of the NASW Standards for Cultural Competence in Social Work Practice. Washington: Author.

Pedersen, P. B., H. C. Crethar, \& J. Carlson (2008). Inclusive Cultural Empathy: Making Relationships Central in Counseling and Psychotherapy. Washington: American Psychological Association.

Race, R. (2011). Multiculturalism and Education. London and New York: Continuum.

Reitz, J. G., R. Breton, K. K. Dion, \& K. L. Dion (eds) (2009). Multiculturalism and Social Cohesion: Potentials and Challenges of Diversity. Dordrecht: Springer.

Rogers, E. M., W. B. Hart, \& Y. Miike (2002). Edward T. Hall and the history of intercultural communication: The United States and Japan. Keio Communication Review, 24, 3-26.

Shaules, J. (2007). Deep Culture: The Hidden Challenges of Global Living. Clevedon: Multilingual Matters.

Shaules, J. (2010). Deep Culture Experience: Beneath the Surface. Boston: Intercultural Press.

Sheldon, B. \& G. Macdonald (2009). A Textbook of Social Work. London and New York: Routledge.

Snow, C. P. (1959/1964). The Two Cultures. New York: Cambridge University Press.

Spitzberg, B. H. (1989). Issues in the development of a theory of interpersonal competence in the intercultural context. International Journal of Intercultural Relations, 13, 241-268.

Stuart, P. H. (2008). Social work profession: History. In: T. Mizrahi \& L. E. Davis (eds), Encyclopedia of Social Work, $20^{\text {th }}$ Edition, Volume 4 (pp. 156-164). Washington: NASW Press and New York: Oxford University Press.

Sue, D. W. (2006). Multicultural Social Work Practice. Hoboken: John Wiley \& Sons, Inc.

Škorić, M. (2004). Kognitivni aspekti antropologije etniciteta. Sociološki pregled 38 (1-2): 281-307. 
Škorić, M. (2006). Predrasude i stereotipi kao elementi antropologije etniciteta. U: M. Tripković (ur.), Multikulturna Vojvodina u evropskim integracijama. Novi Sad: Filozofski fakultet, Odsek za sociologiju, str. 285-307.

Škorić, M. (2010). Sociologija nauke: mertonovski i konstruktivistički programi. Sremski Karlovci i Novi Sad: Izdavačka knjižarnica Zorana Stojanovića.

Škorić, M. i A. Kišjuhas (2012a). Bartova teorija o strukturalnim rupama. U: V. Sokolovska i M. Škorić (ur.), Analiza socijalnih mreža II. Novi Sad: Filozofski fakultet, str. 11-43.

Škorić, M. i A. Kišjuhas (2012b). Glokalizacija kao hibridizacija i heterogenizacija globalnog. U: V. Sokolovska i D. Marinković (ur.), Regioni i regionalizacija: sociološki aspekti. Novi Sad: Mediterran Publishing, str. 63-92.

Škorić, M. i A. Kišjuhas (2014). Vodič kroz ideologije I. Novi Sad: AKO.

Škorić, M. i A. Kišjuhas (2015). Vodič kroz ideologije II. Novi Sad: AKO.

Škorić, M. i A. Tomašević (2011). Granoveterova teorija o snazi slabih veza. Sociološki pregled 45 (3): 323-336.

Tyler, F. B. (2001). Cultures, Communities, Competence, and Change. Springer Science+Business Media, LLC.

Van Wormer, K. (2007). Human Behavior and the Social Environment, Micro Level: Individuals and Families. New York: Oxford University Press.

Watt, D. (2007). Toward a neuroscience of empathy: Integrating affective and cognitive perspectives. Neuropsychoanalysis: An interdisciplinary Journal for Psychoanalysis and the Neurosciences, 9, 119-140.

Wellman, B. (1999). Living networked on and offline. Contemporary Sociology, 28, 648-654. Willett, C. (ed.) (1998). Theorizing Multiculturalism: A Guide to the Current Debate. Maiden: Blackwell Publishers. 